\title{
La evidencia continua siendo insuficiente en cuanto a la utilidad del rastreo de caries en niños realizado por médicos de atención primaria
}

Evidence continues to be insufficient on the usefulness of childhood caries screening performed by primary care physicians

Chou R y col. Pediatrics 2013;132(2):332-350.

\section{Objetivos}

Actualizar la revisión sistemática realizada en 2004 por la Fuerza de Tareas Preventiva Norteamericana (sigla en inglés, USPSTF) sobre la prevención de caries dental de niños menores de cinco años mediante la intervención de médicos de atención primaria.

\section{Fuentes de datos}

Medline (desde enero de 1999 hasta marzo de 2013), base de datos de la Biblioteca Cochrane y revisión de lista de referencias.

\section{Selección de estudios}

Se evaluaron ensayos clínicos controlados aleatorizados, ensayos clínicos controlados no aleatorizados y estudios de Cohorte. Además, se incluyó una revisión actualizada de estudios observacionales sobre riesgo de fluorosis. La búsqueda se realizó con la intención de conocer la efectividad, seguridad y posibles daños colaterales del examen bucal realizado por médicos de atención primaria para diagnosticar caries en la primera infancia. Se evaluaron también tratamientos preventivos (administración de fluoruros o xilitol) que pudieran ser administrados por médicos, padres o tutores sin necesidad de entrenamiento específico.

\section{Extracción de datos}

Fueron evaluados por dos revisores de manera independiente. Los datos fueron extraídos por uno de los autores y luego revisados por otro.

\section{Resultados principales}

La búsqueda bibliográfica arrojó 1.215 citas, de las cuales se revisó el texto completo de 539 publicaciones y se incluyeron 20 estudios. No se encontraron estudios que compararan resultados relacionados a la prevención de caries entre pacientes sometidos o no a examen bucal realizado por médicos de atención primaria, ni que confirmaran la capacidad de estos profesionales para determinar el riesgo de desarrollo de caries en niños. Se observó que aquellos profesionales que recibieron mayor entrenamiento en salud bucal fueron más precisos en el diagnóstico de caries (tabla 1).

No se hallaron nuevos estudios que evaluaran la efectividad del uso de suplementos de flúor administrados por vía oral. Tres ensayos clínicos fueron consistentes con estudios previos en determinar la eficacia del barniz de flúor para reducir el incremento de caries. Se encontraron tres nuevos ensayos no concluyentes con respecto a los efectos preventivos del xilitol sobre el desarrollo de caries. Nuevos estudios observacionales fueron consistentes con la evidencia previa que muestra una asociación entre uso de fluoruro y fluorosis dental.

Tabla 1: Precisión en el diagnóstico de caries realizado por médicos de atención primaria comparado con el diagnóstico realizado por los odontólogos ${ }^{a}$.

\begin{tabular}{c|l|c|c}
$\begin{array}{c}\text { Horas de } \\
\text { entrenamiento } \\
\text { en salud bucal }\end{array}$ & Resultados principales & Sensibilidad & Especificidad \\
\hline $\mathbf{2}$ horas & Identificación de caries & 0,76 & 0,95 \\
\hline & Identificación de necesidad de derivación & 0,63 & 0,98 \\
\hline $\mathbf{4}$ horas & Identificación de caries & 1,0 & 0,87 \\
\hline
\end{tabular}

a Considerado como prueba de referencia.

\section{Conclusión}

No hay suficiente evidencia que sustente la práctica del examen bucal realizado por médicos de atención primaria con el objetivo de reducir las caries en la primera infancia.

Fuente de financiamiento y conflictos de interés de los autores: Agency for Healthcare Research and Quality (AHRQ) for the US Preventive Services Task Force.

\section{Comentario}

La caries dental es un problema crónico común en la infancia ${ }^{1}$ y es cinco veces más frecuente que el asma ${ }^{2}$. Los médicos de atención primaria controlan alrededor de 11 veces a los niños sanos entre el nacimiento y los tres años, y están en una posición privilegiada para detectar patologías bucales, brindar pautas preventivas y derivar al odontólogo. Entre las limitaciones de la revisión aquí resumida se destacan, que la búsqueda excluyó Lilacs y Embase, que solo se incluyeron estudios en idioma inglés y que se excluyeron los que fueron publicados solo como resúmenes. Además, los estudios incluidos no fueron de gran calidad metodológica, por lo que el riesgo de sesgo es alto. De todos modos, se desprende que cuando se entrena a los profesionales, estos son capaces de diagnosticar caries y derivar los pacientes al odontólogo. Si bien no han encontrado evidencia directa, la OMS destaca "la importancia de situar la educación médica en el contexto de una educación multidisciplina-ria y proveer atención primaria de la salud de forma interdisciplinaria"3.

Amalia Alfonsin [ Hospital Italiano de Buenos Aires. amalia.alfonsin @hiba.org.ar ]

Graciela Rasines Alcaraz [ Asociación Odontológica Argentina. mgrasines@gmail.com ]

Amalia Alfonsin y Graciela Rasines Alcaraz. La evidencia continua siendo insuficiente en cuanto a la utilidad del rastreo de caries en niños realizado por médicos de atención primaria. Evid Act Pract Ambul. Ene-Mar 2014;17(1):7. Comentado de: Chou R, Cantor A, Zakher B, Mitchell JP, Pappas M. Preventing dental caries in children <5 years: systematic review updating USPSTF recommendation. Pediatrics 2013;132(2):332-350. PMID: 23858419 .

\section{Referencias}

1. Douglas J, Douglas A, Silk H. A practical guide to infant oral health. Am Fam Physician. 2004;70(11): 2113-2120.

2. United States Public Health Service. Office of the Surgeon General. Oral Health in America: A reporto f the Surgeon General. Rockville, Md. Dept. of Health and Human Services, US Public Health Service, 2000.

3. World Health Organization (OMS), Reorientation of medical education and medical practice for health for all. World health assembly resolution, Ginebra, Suiza: WHA 48.8, World Health Organization; 1995. 